\title{
DEVELOPMENTAL AND CONVALESCENT CHANGES OF THE ANEMIA CAUSED BY EXCESS METHIONINE IN THE RAT
}

\author{
Fumi Yoкотa, Nobuo Matsuno, and Ryokuero SuzuE ${ }^{1}$ \\ The National Institute of Nutrition, \\ 1, Toyama-cho, Shinjuku-ku, Tokyo 162, Japan
}

(Received April 27, 1979)

\begin{abstract}
Summary An experiment was performed to investigate the progressive changes of the anemia caused by excess methionine in rats, during the developmental and convalescent periods. Hemoglobin concentration, hematocrit value and red blood cell count were elevated in the initial stage of excess methionine feeding, they then gradually decreased. During the convalescent period, after ceasing administration of the excess methionine diet, symptoms of anemia gradually disappeared. The nitrogen efficiency ratio was markedly decreased by excess methionine feeding, however, it rapidly recovered after ceasing administration of the excess methionine diet. Iron deposited in the spleen also disappeared quickly during the convalescent period. Of the symptoms of anemia caused by excess methionine, the activity of $\delta$-aminolevulinic acid synthetase (ALAS) in the bone marrow showed the most acute changes. As mentioned previously (1), although lowered globin biosynthesis due to amino acid imbalance could be considered as one of the important causes of the anemia and also would be one of the causes of the compensative elevation of ALAS activity, the possibility still remain that there are other unknown effects of excess methionine on ALAS activity in the bone marrow in this case.

Keywords L-methionine, anemia, $\delta$-aminolevulinic acid synthetase (ALAS)
\end{abstract}

When rats were fed on a low protein diet supplemented with excess methionine, a moderate degree of anemia was manifested within two months. The mechanisms of the anemia caused by excess methionine and its alleviation by glycine have been studied and, the results have been reported previously (1). It is considered that the degradation of hemoglobin is not altered by excess methionine, but the biosynthesis of hemoglobin seems to be inhibited by an amino acid

\footnotetext{
1 横田> ミ, 松野信郎, 鈴江緑衣郎
} 
imbalance. Since the biosynthetic activity of heme itself is considered not to be altered by excess methionine, the cause of anemia in this case would be due to the decreased biosynthesis of globin as a result of excess methionine. In order to confirm these observations and to observe the relations between the markedly higher elevation of ALAS activity and the symptoms of anemia, experiments were performed at the developmental stage and the convalescent period of the anemia caused by excess methionine.

\section{MATERIALS AND METHODS}

Eighty albino rats of the Wistar strain were used in this experiment. Nine \% casein basal diet was the control diet, and basal $+2.5 \%$ L-methionine was the experimental diet. The composition of the basal diet is the same as that described previously (1); that is casein $9 \%$, cornstarch $81 \%$, vitamin mix. $1 \%$, mineral mix. $4 \%$ and soybean oil $5 \%$. Two and a half $\%$ L-methionine was added to the basal diet instead of cornstarch. With an average body weight of $70 \mathrm{~g}$, the rats were fed the basal diet for about one week. With an average body weight of $90 \mathrm{~g}$, the animals were divided into two groups. Prior to starting the experimental diet, six rats were sacrificed by decapitation and the hematological value of the blood and ALAS activity in the bone marrow were determined. The animals then began their respective diets. Water and food were given ad libitum. For nitrogen efficiency determination, rats were kept in individual metabolic cages for three days each week to collect feces and urine. During the experimental period, animals were sacrificed at intervals of one week within the initial three weeks and the results obtained were indicated as a value in the developmental stage of the anemia. After eight weeks of feeding with the respective diets, the experimental animals ceased taking the excess methionine diet, and all animals were fed the basal diet for four weeks, the convalescent period. Animals were also sacrificed at intervals of one week during this period. Hemoglobin concentration, hematocrit value and red blood cell count were determined by conventional methods. Nitrogen in the diet, feces and urine was determined by Kjeldahl's method. ALAS activity in the bone marrow was determined by the method described by UrATA and GRANICK (2). Iron in the spleen was determined by atomic absorption spectrometry after wet ashing of the spleen by acid digestion.

\section{RESULTS AND DISCUSSION}

The hematological changes during the developmental and convalescent periods of the anemia caused by excess methionine are shown in Figs. 1,2 and 3. As shown, after one week on the excess methionine diet, the hemoglobin, hematocrit value and $\mathrm{RBC}$ count were elevated before manifestation of the symptoms of anemia; they then gradually decreased. However, only the hemoglobin values showed statistically significant differences between the control and excess 


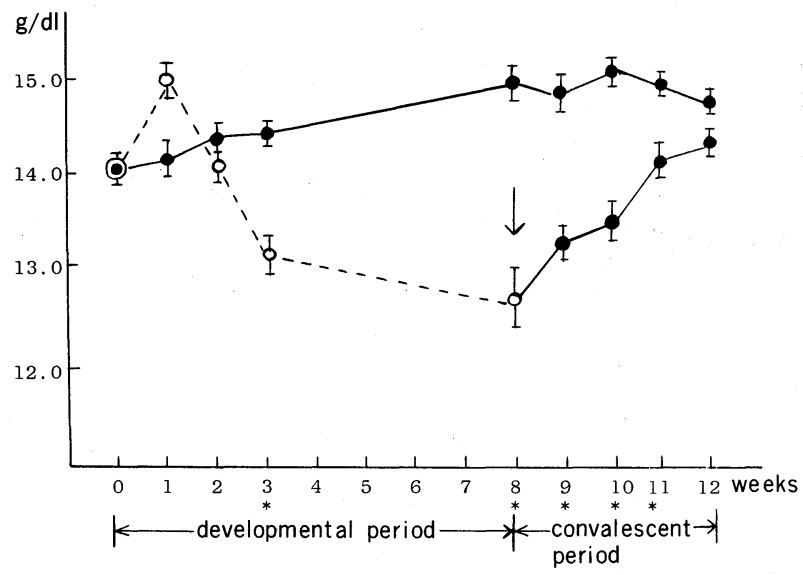

Fig. 1. Changes in blood hemoglobin levels in rats. Rats receiving control diet (- $-\bullet)$, Lmethionine supplemented diet $(2.5 \mathrm{~g} / 100 \mathrm{~g}$ diet $)\left(\mathrm{O}^{-} \mathrm{-}\right)$. Each point represents mean $\pm \mathrm{SE}$ for 5 or 6 animals in each group. Differences between two groups in the weeks with an asterisk (with the exception of weeks 4 to 7 which were not determined) are statistically significant $(p<0.05)$.

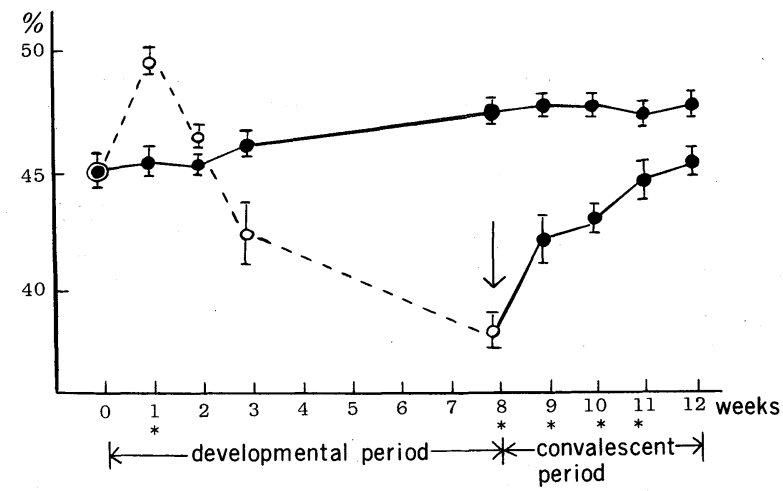

Fig. 2. Changes in blood hematocrit values in rats. Rats receiving control diet $(\bullet-\bullet)$, Lmethionine supplemented diet $\left(2.5 \mathrm{~g} / 100 \mathrm{~g}\right.$ diet) $\left(\mathrm{O}^{-}-\mathrm{O}\right)$. Each point represents mean $\pm \mathrm{SE}$ for 5 or 6 animals in each group. Differences between two groups, in weeks with an asterisk (with the exception of weeks 4 to 7 which were not determined) are statistically significant $(p<0.05)$.

methionine groups at the end of three weeks of feeding with the excess methionine diet. After eight weeks, the hemoglobin, hematocrit value and RBC count were markedly reduced in the excess methionine group of rats. During the convalescent period, after ceasing administration of the excess methionine diet, the hemoglobin, hematocrit value and RBC count gradually rose. At the end of four weeks of the convalescent period, hemoglobin and hematocrit values had almost recovered to 


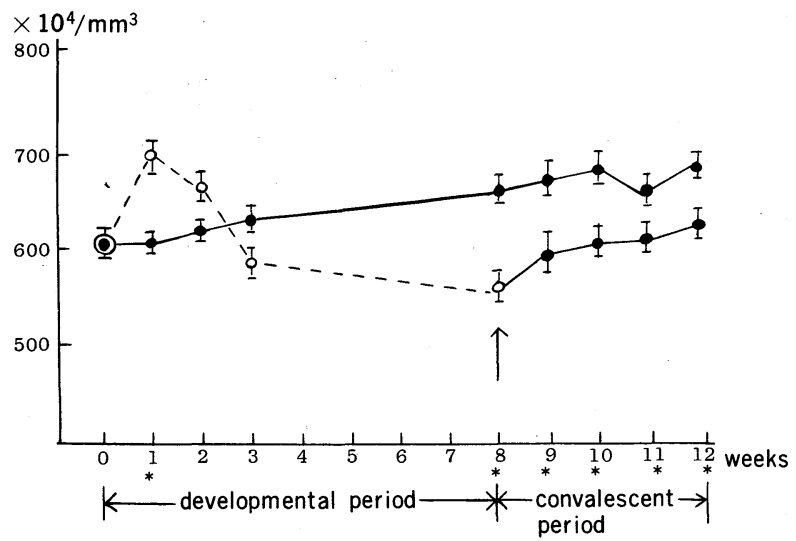

Fig. 3. Changes in RBC count in rats. Rats receiving control diet (- $\bullet$ ), L-methionine supplemented diet $(2.5 \mathrm{~g} / 100 \mathrm{~g}$ diet $)(0--0)$. Each point represents mean \pm SE for 5 to 6 animals in each group. Differences between two groups, in weeks with an asterisk (with the exception of weeks 4 to 7 which were not determined) are statistically significant $(p<0.05)$.

Table 1. Nitrogen efficiency ratio ${ }^{1}(\%)$

\begin{tabular}{|c|c|c|c|}
\hline \multirow{2}{*}{\multicolumn{2}{|c|}{ Weeks }} & \multicolumn{2}{|c|}{ Diet } \\
\hline & & Basal & Basal $+2.5 \%$ L-methionine \\
\hline \multirow[t]{4}{*}{ I. } & Developmental period & & \\
\hline & 1 & $60.6^{\mathrm{a}, *} \pm 3.1^{* *}$ & $57.9^{\mathrm{a}} \pm 3.0$ \\
\hline & 2 & $60.5^{\mathrm{a}} \pm 4.3$ & $22.2^{\mathrm{b}} \pm 4.8$ \\
\hline & 3 & $59.5^{\mathrm{a}} \pm 4.2$ & $2.1^{c} \pm 5.6$ \\
\hline \multirow[t]{5}{*}{ II. } & Convalescent period & & \\
\hline & 1 & $72.7^{\mathrm{a}} \pm 1.4$ & $75.2^{\mathrm{a}} \pm 1.4$ \\
\hline & 2 & $72.6^{\mathrm{a}} \pm 1.0$ & $75.8^{\mathrm{a}} \pm 0.5$ \\
\hline & 3 & $71.6^{\mathrm{a}} \pm 2.0$ & $76.1^{\mathrm{a}} \pm 1.4$ \\
\hline & 4 & $71.0^{\mathrm{a}} \pm 2.4$ & $76.5^{a} \pm 0.7$ \\
\hline
\end{tabular}

1 Nitrogen efficiency ratio was calculated by the following formula. $\mathrm{N}$ intake $=\mathrm{a} \mathrm{mg}, \mathrm{N}$ in urine $=b \mathrm{mg}, \mathrm{N}$ in feces $=\mathrm{cmg}, \mathrm{N}$ balance $\mathrm{d}=\mathrm{a}-(\mathrm{b}+\mathrm{c}) \mathrm{mg}, \mathrm{N}$ efficiency ratio $=\mathrm{d} / \mathrm{a}(\%)$.

* Means having same superscripts are not significantly different $(p<0.01)$.

** Mean \pm SE.

the control level. RBC count also indicated some recovery.

The nitrogen efficiency ratio for each week of the developmental and convalescent periods are shown in Table 1 . As shown, during the developmental period of the anemia, the nitrogen efficiency ratio was markedly reduced in the 
excess methionine group. However, immediately administration of the excess methionine diet ceased, it rapidly recovered to the control level. This indicates that nitrogen efficiency in rats is greatly affected by addition of excess methionine.

Iron deposited in the spleen of rats is shown in Fig. 4. Iron deposition was markedly elevated by excess methionine feeding; after eight weeks it was $170 \mu \mathrm{g} / 100 \mathrm{mg}$ of spleen, that is over 4 times higher than the control level of $37 \mu \mathrm{g} / 100 \mathrm{mg}$ of spleen. However, when administration of excess methionine ceased, iron deposited in the spleen gradually disappeared, and after four weeks of the convalescent period, it returned to a normal level. With regard to this increased iron deposition in the spleen of rats fed on excess methionine, as stated previously (1), it is speculated that the deposited iron had not been utilized because of lowered hemoglobin biosynthesis. This is probably true since, in this experiment, the iron deposited in the spleen soon disappeared after ceasing administration of excess methionine.

Progressive changes in $\delta$-aminolevulinic acid synthetase activity in the bone marrow are shown in Table 2. Among the items which were examined in this

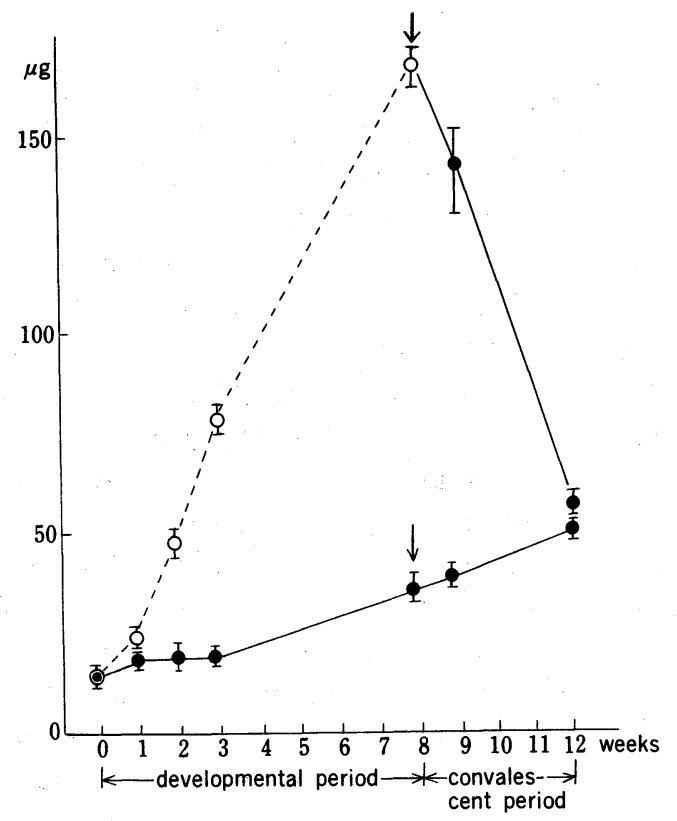

Fig. 4. Changes in the iron contents in the spleen of rats $(\mathrm{Fe} \mu \mathrm{g} / 100 \mathrm{mg}$ of wet tissue). Rats


represents mean \pm SE for 5 to 6 animals in each group. Values determined are significantly different between the corresponding two groups $(p<0.01)$, with the exception of weeks 1 and 12. 
Table 2. $\delta$-Aminolevulinic acid synthetase activities in the bone marrow. ${ }^{1}$

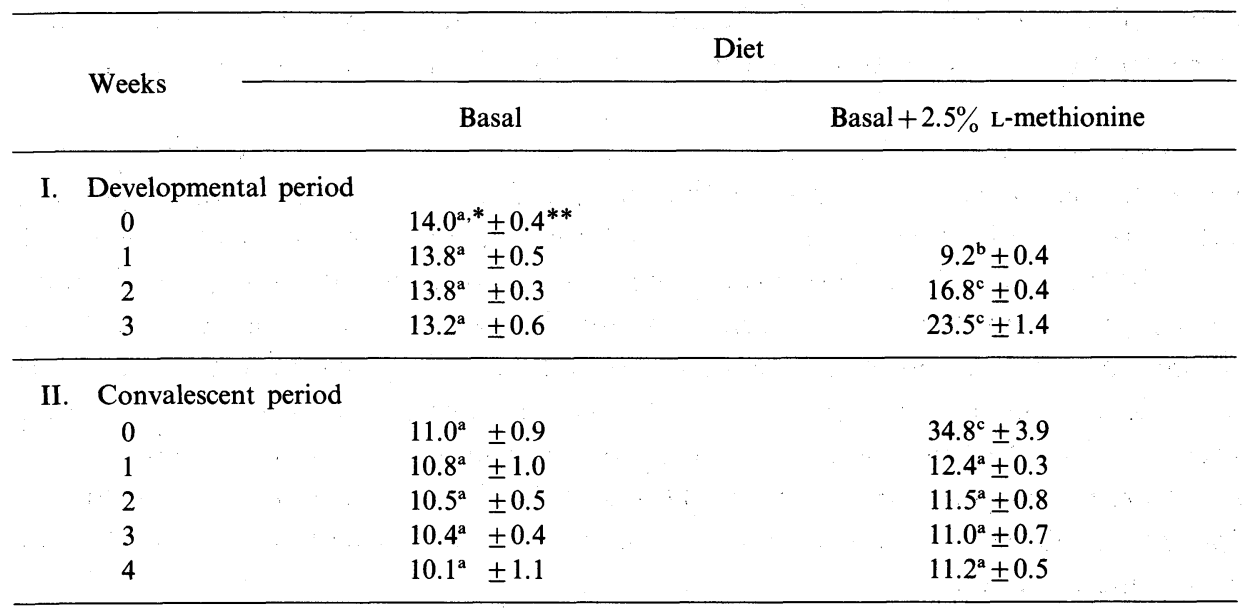

${ }^{1}$ Enzyme activities are expressed as $\mu \mathrm{g}$ of PBG formed per hour of incubation per $100 \mathrm{mg}$ of bone marrow.

* Means having same superscripts are not significantly different $(p<0.01)$.

** Mean \pm SE.

experiment, the most marked changes were observed in ALAS activity. During the developmental stage of anemia, after one week of feeding, ALAS activity decreased in the excess methionine group, simultaneously with the elevation of hematological value in this period; afterwards it rapidly increased. At the end of eight weeks, it was more than three times higher than the control value. However, when administration of the excess methionine diet ceased, it descended to the control level within one week. It is well known that this enzyme is a key enzyme in heme biosynthesis and changes sensitively with symptoms of anemia. The enzyme activity in the bone marrow also shows a compensative elevation in anemia in other cases such as lead poisoning or ascorbic acid deficiency and anemia caused by hemorrhage. However, the most marked elevation of this enzyme's activity is observed in the anemia caused by excess methionine. As mentioned previously $(I)$, although lowered globin biosynthesis due to amino acid imbalance could be considered an important cause of the anemia in excess methionine, and in addition a cause of the elevation of this enzyme's activity in this case, there may be numerous other unknown factors (3-6). In order to clarify and to confirm these observations, further investigations are necessary on the metabolic relations between excess methionine and $\delta$-aminolevulinic acid synthetase activity in the bone marrow.

\section{REFERENCES}

1) Yokota, F., Esashi, T., and Suzue, R. (1978): Nutritional anemia induced by excess methionine 
in rat and the alleviative effects of glycine on it. J. Nutr. Sci. Vitaminol., 24, 527-533.

2) Urata, G., and Granick, S. (1963): Biosynthesis of $\alpha$-amino ketones and the metabolism of aminoacetone. J. Biol. Chem., 238, 811-820.

3) Benevenga, N. J. (1974): Toxicities of methionine and other amino acids. J. Agric. Food Chem., 22, 2-9.

4) UChino, H., and Itokawa, Y. (1972): Studies on nutritional value of $S$-methylcysteine sulfoxide. (I) Effect of increased dietary $S$-methylcysteine sulfoxide on growth and tissues in rats. Jpn. $J$. Hyg., 27, 248-252.

5) UCHINo, H., and ItoKaWA, Y. (1972): Studies on nutritional value of $S$-methylcysteine sulfoxide (II) Splenic hypertrophy of rats on an increased $S$-methylcysteine sulfoxide diet and effect of $S$ methyl cysteine sulfoxide administration on splenectomized rats. Jpn. J. Hyg., 27, 253-256.

6) UCHINo, H. (1973): Nutritional value of $S$-methylcysteine sulfoxide. (III) Comparison of $S$ methylcysteine sulfoxide, $S$-allylcysteine sulfoxide and related sulfur-containing amino acids. Jpn. J. Hyg., 28, 385-391. 